\title{
Safer Sexual Practices and HIV Screening Behavior among Rural California American Indians
}

\author{
Felicia S. Hodge ${ }^{1}$ and Karabi Sinha ${ }^{2}$ \\ ${ }^{1}$ University of California, Los Angeles, School of Nursing and School of Public Health \\ ${ }^{2}$ University of California, Los Angeles, School of Nursing \& \\ School of Public Health, Department of Biostatistics
}

\begin{abstract}
This paper reports on safer sexual practices and HIV screening behavior among rural California American Indians. Thirteen Indian health clinic registries formed the random household survey sampling frame ( $\mathrm{N}=457)$. Measures included socio-demographics, safer sexual practices, HIV testing, high-risk behaviors, perception of wellness, general health status, neglect, physical and sexual abuse history. Statistical tests included chi-square and Fisher's exact tests, as well as multiple logistic regression analysis. Respondents who practiced safer sex were younger, not married, reported lower annual income, changed sexual behavior in the last 12 months, were not in a monogamous relationship, and had a higher perception of wellness. Those who were tested for HIV were younger, had at least a high school education, consumed alcohol, had significantly higher suicide ideation and attempts, changed their sexual behavior in the last 12 months, and reported a history of sexual abuse as a child and adult. Very little is known about HIV prevention and screening behaviors in rural American Indian populations. Identifying predictors of unsafe sexual practices and non-HIV testing tendencies help to plan for measures to protect the population from this devastating disease. We make recommendations for implementing HIV prevention education and screenings at American Indian clinics.

(C) 2008 Californian Journal of Health Promotion. All rights reserved.

Keywords: American Indian, HIV screening, safer sex practices, rural populations, HIV education
\end{abstract}

\section{Introduction}

The human immunodeficiency virus (HIV) and resulting autoimmunodeficiency syndrome (AIDS) pose a major threat to American Indians and Alaska Natives. Little is known about HIV screening and safer sexual practices among this population. Although American Indians represent less than $1 \%$ of those with HIV/AIDS, they have the third highest prevalence of HIV/AIDS diagnosis (10.4 per 100,000), after African Americans and Hispanics (CDC, 2008). This paper reports on the characteristics of the adult rural American Indian who practice safer sexual behaviors and obtain HIV screening in rural California sites. Healthy People 2010 recommend promoting safer sexual behaviors through increasing knowledge about HIV risk and improving access to HIV testing and health care services, both of which are much needed in American Indian populations (USDHHS, 2000).

From the 1980s - 2005, a total of 3,300 American Indians and Alaska Natives were diagnosed with HIV/AIDS (CDC, 2008); American Indian women account for $29 \%$ of those diagnosed (CDC, 2008). At the end of 2007, an estimated 3,492 American Indians and Alaska natives in the United States were living with HIV infection (CDC, 2008). Although the prevalence of HIV/AIDS is lower in this population as compared to other ethnic and racial groups, American Indians face poor survival. American Indians and Alaska Natives 
experience a much shorter survival rate after receiving an HIV/AIDS diagnosis than Asian Pacific Islanders, Whites, or Hispanics (CDC, 2008). The percentage of American Indians and Alaska Natives surviving nine years after HIV/AIDS diagnosis is $67 \%$, compared to $66 \%$ of African Americans, 74\% of Hispanics, 75\% of whites, and $81 \%$ Asian Pacific Islanders (CDC, 2008). This may be explained by limited access to health care services (U.S. Commission on Civil Rights, 2003).

\section{Characteristics and Modes of HIV Exposure among American Indians/Alaska Natives} Approximately 550 American Indian tribes exist in the U.S. and four million American citizens self-identify either as American Indian, Native American, or Alaska Native (Bureau of Indian Affairs, 2008). American Indian and Alaska Native persons with HIV/AIDS are more likely to be younger in age than non-Native persons with HIV/AIDS (CDC, 2008). Although the majority of American Indians and Alaska Natives are exposed to HIV through male-tomale sexual contact or injection drug use, the percentage of this population contracting HIV through heterosexual contact is increasing (CDC, 2008).

\section{HIV Education, Counseling, and Screening Behaviors}

When high-risk, vulnerable populations are given culturally-appropriate information about safer sexual practices, the transmission of HIV and other sexually transmitted infections (STI) is reduced (Bolu, et al., 2004; Darbes, et al., 2005). In a study by Bolu et al. self-reported condom use is higher after participants take part in short counseling interventions and $20 \%$ fewer participants had new STIs after a one year follow up. Darbes et al. (2008) report that interventions that significantly reduce unprotected sex and the sexual transmission of infectious diseases include cultural-tailoring and education on correct use of condoms along with communication skills needed for negotiating safer sex. In a study describing HIV risk behaviors, perceptions, and HIV testing among American Indians, almost half $45 \%(n=218)$ rate their behavior as "potentially high risk," and $83 \%$ of the total sample report having received an HIV test at least once during their lifetime (Lapidus, Bertolli, McGowan, \& Sullivan, 2006). A study of sexually active American Indians and Alaska Native adolescents reports a lower rate of unprotected sex compared to the national average (Marsiglia, Nieri, \& Stiffman, 2006). However, investigators attribute this particular finding to the likelihood of their sample living in an urban environment leading to access to HIV education in their school district, as well as their having access to condoms. In another study, $78 \%(n=134)$ of patients in an alcohol/drug treatment center agreed to HIV testing and returned for their results after receiving an HIV prevention educational program (Foley, Duran, Morris, et al., 2005). Therefore, according to findings from prior research, HIV risk behaviors and perception of risk are independently associated with HIV testing, and vulnerable populations are amenable to HIV education and testing. Yet, HIV incidence and prevalence through heterosexual contact continue to increase among American Indians and Alaska Natives.

The Centers for Disease Control and Prevention (CDC, 2004) recommends routine HIV counseling and testing as part of standard, regular medical care services, irrespective of risk behavior or pregnancy status. The recommended age group for testing is ages 16 through 64 . According to the CDC (2004), approximately 1 million persons are living with HIV infection in the US; however, $25 \%$ of these persons do not know they have HIV and thus are left untreated and/or undiagnosed. This paper reports on the characteristics of adult rural American Indians who practice safer sexual behaviors and obtain HIV screening in rural California sites.

\section{Methods}

\section{Recruitment}

The Indian Health Service reports that the majority of rural American Indians utilize Indian healthcare clinic services for their health care (Indian Health Service, 2009). In California, approximately 75,000 American Indians are active patients at 36 rural Indian Health clinics and an additional 60,000 are served by 8 urban Indian clinics (Indian Health Service, 2009). 
Because many of the rural clinics report small numbers of active patients, rural Indian clinics with larger numbers of active patients were selected as a focal point to identify and access the population in this study. Fifteen rural clinics with a reported active service population of over 1,000 American Indians each were approached and invited to participate in the study. Through a process of collaboration and agreement, thirteen Indian health clinic sites agreed to participate in the study.

Site approvals were obtained through letters of agreement from each site and/or clinic. Institutional Review Board approvals were obtained from the University of California at Berkeley, the University of California at San Francisco, the University of Minnesota and the Indian Health Service. Participants were provided verbal and written information on the study and informed consent took place either in their households or at the clinic. The voluntary nature of the study was explained, carefully noting that services at the tribal, clinic or community centers were not contingent upon their participation in the study.

\section{Sample}

The study sample was comprised of American Indians aged 18 years and older, who were active clients of the local Indian healthcare clinic (defined as clinic user within the past 5 years), residing within the service area of the local rural reservation/rancheria site and a member of the selected study household. Five hundred adult American Indians were recruited into the study and 457 agreed to participate.

\section{Design}

The study design was a cross-sectional household study of 13 rural California reservation sites. Fifteen healthcare clinics sites were approached and 13 agreed to participate in the study. American Indian households were identified through the clinic health registries, which formed the sampling frame for a random household survey. Households were then randomly selected and a self-administered questionnaire was given to all adult members of participating households.

\section{Data Collection Method}

We modified the 1998 Behavioral Risk Factor Surveillance System (BRFSS) survey (CDC, 1998) to include questions relating to abuse and neglect. All household members were contacted by telephone, US mail, and by personal contact to recruit into the project. Sixty percent of respondents chose to complete the survey in their homes; the remainder filled out the questionnaire at a private clinic meeting room.

\section{Measures}

The survey instrument was a 60 minute questionnaire that included the following measures:

Socio-demographic characteristics: Gender, tribal affiliation, degree of Indian blood, employment, income and educational attainment. Age was grouped into cohorts (1824, 25-39, 40-54, and 55+). Marital status was dichotomized into married (or living with someone) and single (divorced/separated/widowed/single).

Perceived wellness status: Respondents were asked, "Wellness includes feeling good and taking care of yourself physically, emotionally, mentally and spiritually. How would you rate your own wellness?" This measure was dichotomized into two categories $(\operatorname{good}=$ excellent/very good and poor $=$ fair/good).

General health status: A single question, "How would you rate your health, nowadays? Would you say that it is excellent, very good, fair or poor?" was used to measure health status. This measure was dichotomized into two categories (good $=$ excellent $/$ very good and poor $=$ fair/poor).

High risk behaviors: Current smoking status (smoked over 100 cigarettes in lifetime plus current smoker), intention to quit smoking (in next 30 days), 5 or more drinks of alcohol within the past 30 days, suicide ideation and suicide attempts are measured. Data on drug usage was

not reported in this paper due to the low response rate and concern that responses were 
not truthful due to fears, stigma, legal and family issues.

\section{Sexual Practice}

All respondents were asked if they practiced safer sex (use a condom); if they changed their sexual behavior in last 12 months; were in a monogamous relationship, were celibate (no intercourse), if they had a HIV test, and if they had received results of an HIV test. History of childhood, adolescent, or adult physical, mental or sexual abuse and neglect were asked.

\section{Data Analysis}

Two independent classifier effects were assessed for this sample of American Indians: 1) whether a person got tested for HIV or not; 2) whether a person practiced safer sex or not. Differences between these categories were studied under the broad classes of demographics, perception of wellness, health status, high-risk behaviors, sexual practices/behaviors and neglect and abuse history. Chi-square tests and Fisher's exact tests were used to assess statistical differences between categories. Multiple logistic regression models were built separately to obtain predictors of practicing safer sex and being tested for HIV using a backward selection procedure. Predictors included variables that were associated with safer sex (or being tested for HIV) in preliminary analyses; covariates were retained if they were significant at the 0.10 level. Model fit was assessed by the Hosmer and Lemeshow Goodness-of-Fit statistic (Hosmer \& Lemeshow, 2000). All model assumptions were checked and met. All statistical analyses were performed with a Statistical Analysis Program (SAS/STAT).

\section{Results}

\section{Demographic characteristics}

The sample consisted of 457 rural American Indian adults who were recruited into a randomized household survey at 13 sites in California. The sample was primarily female (74.2\% female), with an average age of 44.79 $(\mathrm{sd}=15.88)$ and ranging from 28 to 75 years old. Nearly a quarter, $24.4 \%$, had less than a high school education. The average annual household income was $\$ 24,468.84$ (sd = 19931.33) and the majority were married or living together $(52.4 \%)$. The majority of households $(82 \%)$ reported having a telephone in their homes. Eighty-seven percent were enrolled in a tribe and $43 \%$ of the sample reported that they had $50 \%$ or more Indian blood quantum.

\section{Testing for HIV}

Table 1 reports the demographic characteristics of American Indian adults who reported that they had been tested for HIV versus those who had not. Four hundred and twenty-three out of 457 respondents in the sample (93\% response rate) answered questions about having their blood tested for the HIV virus. Those who responded to the question on testing for HIV, HIV had a mean age of 44 years (range of 18-74 years) and an average annual household income of $\$ 24,774$. Sixty-three percent were employed, $26 \%$ were male, $22 \%$ had less than a high school education, and $52 \%$ was either married or living as married. $\quad(\mathrm{p}=0.03)$, consumed alcohol $(p=0.003)$, had suicidal ideation $(p=0.04)$ and had attempted suicide $(\mathrm{p}=0.06)$ compared to the group who had not been tested for HIV. Selfreported histories of sexual abuse in childhood and in adulthood were significant $(\mathrm{p}=0.002$ and $\mathrm{p}=0.05$, respectively), with a higher proportion of persons who were tested reporting history of abuse. A larger proportion of those who were tested for HIV reported that they practiced safer sex, changed their sexual behavior in the past 12 months $(p=0.0001)$, were celibate $(p=0.07)$, reported good general health status and exhibited high risk behaviors, such as cigarette smoking $(\mathrm{p}=0.09)$. Furthermore, those who had been tested for HIV were generally younger $(\mathrm{p}=0.0001)$ and more educated

A smaller proportion of the sample that had not been tested reported that they were in a nonmonogamous relationship as compared to the HIV tested group. A large proportion of the non- 
Table 1

Characteristics of American Indian Adults Who Get Tested for HIV vs. Those Who Do Not

\begin{tabular}{|c|c|c|c|c|}
\hline Characteristics & $\begin{array}{c}\text { Overall } \\
(n=423)\end{array}$ & $\begin{array}{c}\text { Tested for HIV } \\
\text { YES }(n=171)\end{array}$ & $\begin{array}{c}\text { Tested for HIV } \\
\text { NO }(n=252)\end{array}$ & p-value \\
\hline Demographics & Mean (SE) & Mean (SE) & Mean (SE) & \\
\hline Age & $44.34(15.86)$ & $39.28(12.63)$ & $47.91(16.93)$ & $<.0001^{*}$ \\
\hline \multirow[t]{2}{*}{ Annual household income } & $24774(20021)$ & $24575(22603)$ & $24954(17509)$ & 0.91 \\
\hline & $\%$ & $\%$ & $\%$ & \\
\hline Male & 25.83 & 26.90 & 25.10 & 0.68 \\
\hline \multicolumn{5}{|l|}{ Marital Status } \\
\hline Married or Living w/ someone & 52.30 & 57.32 & 49.00 & \\
\hline Divorced/Separated/Widowed/Single & 47.70 & 42.68 & 51.00 & 0.10 \\
\hline Employed & 62.86 & 68.10 & 59.44 & 0.08 \\
\hline Education ( $\geq$ HS degree) & 77.78 & 83.04 & 74.21 & $0.03 *$ \\
\hline \multicolumn{5}{|l|}{ Health } \\
\hline Fair/Poor Perception of General Health & 57.58 & 55.56 & 58.96 & 0.49 \\
\hline Poor Perception of wellness & 25.78 & 30.36 & 22.67 & 0.08 \\
\hline \multicolumn{5}{|l|}{ High Risk Behaviors } \\
\hline Current Smoker & 36.17 & 40.94 & 32.94 & 0.09 \\
\hline Not quit smoking & 72.54 & 69.23 & 75.32 & 0.42 \\
\hline Alcohol Ever ( $\geq 12$ drinks) & 82.06 & 89.47 & 78.14 & $0.003^{*}$ \\
\hline Suicide ideation & 20.59 & 25.61 & 17.21 & $0.04 *$ \\
\hline Attempted suicide & 8.15 & 11.24 & 6.05 & 0.06 \\
\hline \multicolumn{5}{|l|}{ Sex Practice } \\
\hline Changed sexual behavior in last $12 \mathrm{mo}$. & 26.85 & 38.36 & 17.96 & $<.0001^{*}$ \\
\hline Monogamous relationship & 80.99 & 83.09 & 79.05 & 0.39 \\
\hline Celibate & 21.69 & 22.50 & 20.93 & 0.76 \\
\hline Practiced Safer Sex & 35.04 & 40.44 & 29.71 & 0.06 \\
\hline \multicolumn{5}{|l|}{ Neglect and Abuse } \\
\hline Neglect-Childhood & 17.46 & 20.12 & 15.61 & 0.24 \\
\hline Neglect-Adolescence & 19.38 & 20.27 & 18.75 & 0.72 \\
\hline Neglect- Adult & 13.26 & 14.47 & 12.44 & 0.57 \\
\hline Physical abuse -Childhood & 16.50 & 18.90 & 14.83 & 0.28 \\
\hline Physical abuse - adolescence & 13.04 & 13.82 & 12.50 & 0.71 \\
\hline Physical abuse - Adult & 20.00 & 23.31 & 17.67 & 0.17 \\
\hline Sexual abuse - Childhood & 14.07 & 20.63 & 9.52 & $0.002^{*}$ \\
\hline Sexual abuse - Adolescence & 10.35 & 12.84 & 8.68 & 0.20 \\
\hline Sexual abuse - Adult & 9.55 & 13.13 & 7.14 & $0.05^{*}$ \\
\hline
\end{tabular}

*significant difference between classifiers based on Chi-square or Fisher's Exact test at alpha $=0.05$ 
Table 2

Characteristics of American Indian Adults Who Practice Safer Sex versus Those Who Do Not

\begin{tabular}{|c|c|c|c|c|}
\hline Characteristics & $\begin{array}{l}\text { Overall } \\
(\mathbf{n}=\mathbf{2 8 0})\end{array}$ & $\begin{array}{l}\text { Practice Safer Sex } \\
\text { YES (n=98) }\end{array}$ & $\begin{array}{l}\text { Practice Safer Sex } \\
\text { NO }(n=182)\end{array}$ & p-value \\
\hline Demographics & Mean (SE) & Mean (SE) & Mean (SE) & \\
\hline Age & $44.78(0.77)$ & $37.36(1.22)$ & $42.08(1.01)$ & $0.004 *$ \\
\hline \multirow[t]{2}{*}{ Annual household income } & $25423(20937)$ & $24137(20052)$ & $26203(21569)$ & 0.62 \\
\hline & $\%$ & $\%$ & $\%$ & \\
\hline Male & 28.67 & 27.84 & 29.12 & 0.82 \\
\hline \multicolumn{5}{|l|}{ Marital Status } \\
\hline Married or Living with someone & 60.58 & 44.33 & 69.49 & \\
\hline Divorced/Separated/Widowed/Single & 39.42 & 55.67 & 30.51 & $<0.0001 *$ \\
\hline Employed & 69.60 & 74.74 & 66.85 & 0.18 \\
\hline Education ( $\geq$ HS degree) & 79.29 & 84.69 & 76.37 & 0.10 \\
\hline \multicolumn{5}{|l|}{ Health } \\
\hline Fair/Poor Perception of General Health & 55.71 & 50.00 & 58.79 & 0.16 \\
\hline Poor Perception of Wellness & 26.45 & 19.79 & 30.00 & 0.07 \\
\hline \multicolumn{5}{|l|}{ High Risk Behaviors } \\
\hline Current Smoker & 41.79 & 46.94 & 39.01 & 0.20 \\
\hline Not quit smoking & 72.97 & 60.47 & 80.88 & $0.02 *$ \\
\hline Alcohol Ever ( $\geq 12$ drinks) & 85.36 & 85.71 & 85.16 & 0.90 \\
\hline Suicide ideation & 24.18 & 22.11 & 25.28 & 0.56 \\
\hline Attempted suicide & 10.11 & 10.31 & 10.00 & 0.94 \\
\hline Did not get tested for HIV & 50.36 & 42.71 & 54.49 & 0.06 \\
\hline \multicolumn{5}{|l|}{ Sex Practice } \\
\hline Changed sexual behavior in last $12 \mathrm{mo}$ & 34.96 & 62.22 & 21.02 & $<.0001^{*}$ \\
\hline Monogamous relationship & 78.52 & 67.86 & 83.72 & $0.004 *$ \\
\hline Celibate & 18.45 & 24.69 & 15.13 & 0.07 \\
\hline \multicolumn{5}{|l|}{ Neglect and Abuse } \\
\hline Neglect-Childhood & 19.01 & 15.05 & 21.18 & 0.23 \\
\hline Neglect-Adolescence & 20.41 & 15.29 & 23.13 & 0.15 \\
\hline Neglect- Adult & 13.89 & 13.95 & 13.86 & 0.98 \\
\hline Physical abuse -Childhood & 18.11 & 14.89 & 19.88 & 0.31 \\
\hline Physical abuse - Adolescence & 14.06 & 9.09 & 16.77 & 0.10 \\
\hline Physical abuse - Adult & 23.11 & 21.35 & 24.00 & 0.63 \\
\hline Sexual abuse - Childhood & 16.98 & 15.96 & 17.54 & 0.74 \\
\hline Sexual abuse - Adolescence & 10.67 & 12.50 & 9.70 & 0.49 \\
\hline$\underline{\text { Sexual abuse }- \text { Adult }}$ & 12.41 & 13.98 & 11.56 & 0.57 \\
\hline
\end{tabular}

*: significant difference between classifiers based on Chi-square or Fisher's Exact test at alpha $=0.05$

HIV tested group reported higher levels of perceived. There was very little or no difference between the group who had undergone HIV testing and those who had not in areas of income, gender, general health status and current cigarette smoking (60\%); both groups had no intention to quit smoking in the near future and reported neglect and physical abuse. 


\section{Practicing Safer Sex}

Table 2 reports on the demographic characteristics of those who practiced safer sex and those who had not. Despite the 93\% response rate to the question on having been tested for HIV, only $61 \%$ of survey respondents replied to the question about whether they practiced safer sex. The study sample was fairly evenly divided between those who said they were not practicing safer sex $(n=182,40 \%)$, and those who did not respond to the question $(n=177,39 \%)$. Only $35 \%(n=98)$ of respondents who answered said they were practicing safer sex (see Figure 1). Among those who responded, nearly a third was male; the mean age was 45 years (range of 18-74 years), and 20\% had less than a high school education. Seventy percent of those who answered the question about practicing safer sex were employed with an average annual household income over $\$ 25,000$; $61 \%$ was either married or living as married.

Table 2 shows that those individuals who reported practicing safer sex were significantly younger $(p=0.003)$, single, divorced, widowed or separated $(p=0.0001)$, reported lower annual household income $(p=0.01)$. They generally had changed their sexual behavior in the last 12 months $(\mathrm{p}=0.0001)$, were not in a monogamous relationship $(\mathrm{p}=0.004)$ and tended to report being celibate $(25 \%, \mathrm{p}=0.007)$. Those who practiced safer sex were heavy cigarette smokers (47\%) who reported higher intention to quit smoking compared to the group who had not practiced safer sex $(\mathrm{p}=0.02)$. A larger proportion of the group was employed, more highly educated, had a stronger perception of wellness and reported good general health status.

Those who reported that they did not practice safer sexual behavior had not changed sexual behavior in the last 12 months $(\mathrm{p}=0.0001)$ were generally in a monogamous relationship $(\mathrm{p}=0.004)$, and tended to be less celibate $(\mathrm{p}=0.07)$. A higher proportion also reported that they had not been tested for HIV $(\mathrm{p}=0.06)$.
Figure 1: HIV Testing \& Safer Sex Practices Rural California Adult American Indians $\mathrm{N}=457$

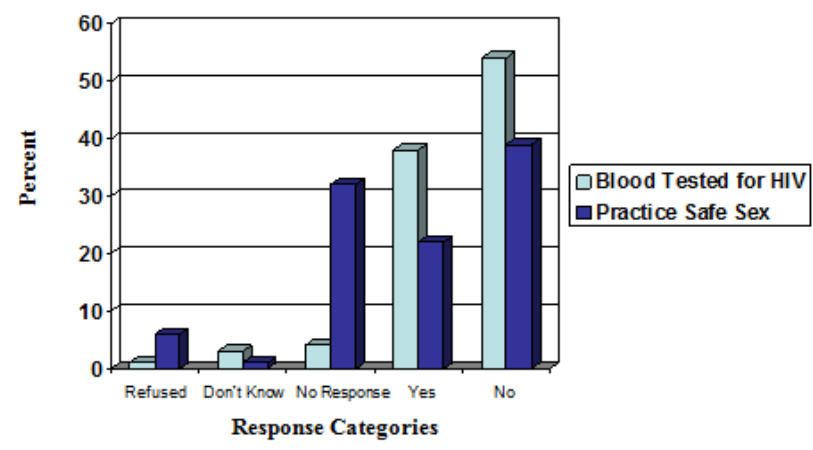

Unlike the significant difference found between the groups having been and having not been tested for HIV, there was no statistical difference between the group who practiced safer sex and those who had not with regard to reported history of neglect, sexual and physical abuse. In addition, both groups (those who practiced safer sex and those who had not) reported little or no difference in high-risk behaviors, such as alcohol consumption, suicide ideation and suicide attempts. Overall, there were few differences found among the reporting of male and female respondents in the study with regard to having practiced safer sex or having obtained an HIV blood test.

\section{Predictors of those who got tested and practiced safer sex}

Tables 3 shows the result of a logistic regression analysis where the outcome was whether a person had been tested for HIV (or not). Table 4 similarly shows the results from a logistic regression model where the outcome was whether a person practiced safer sex (or not). Significant predictors for persons tested for HIV (versus not tested) included age, education, employment status, ever attempted suicide and changed sexual behavior. Younger age $(\mathrm{p}=0.0005)$, having had at least high school education $(\mathrm{p}=0.02)$ and being employed at the time $(\mathrm{p}=0.05)$ were strong predictors of persons 
Table 3

Logistic Regression Comparing Persons Who Got Tested for HIV versus Those Who Did Not

\begin{tabular}{|c|c|c|c|c|c|}
\hline & Estimated $\beta$ & SE (est. $\beta)$ & Estimated OR & $\begin{array}{l}95 \% \text { CI } \\
\text { (for OR) }\end{array}$ & p-value \\
\hline \multicolumn{6}{|l|}{ Covariates } \\
\hline Age & -0.03 & 0.01 & 0.97 & $0.95-0.99$ & $0.005^{*}$ \\
\hline$\geq \mathrm{HS}$ vs $<\mathrm{HS}$ & 0.99 & 0.42 & 2.71 & $1.18-6.23$ & $0.02 *$ \\
\hline Employed vs not & 0.70 & 0.35 & 2.01 & $1.01-4.00$ & $0.05^{*}$ \\
\hline Attempted Suicide vs Not & 1.08 & 0.60 & 2.96 & $0.91-9.57$ & 0.07 \\
\hline $\begin{array}{l}\text { Changed Sexual Behavior vs } \\
\text { Not }\end{array}$ & 0.72 & 0.37 & 2.05 & $1.00-4.20$ & $0.05 *$ \\
\hline $\begin{array}{l}\text { Sexual Behavior (non- } \\
\text { response) vs Did not change }\end{array}$ & -0.58 & 0.48 & 0.56 & $0.22-1.44$ & 0.23 \\
\hline
\end{tabular}

Table 4

Logistic Regression Comparing Persons Who Practiced Safer Sex versus Those Who Did Not

\begin{tabular}{lccccc}
\hline \hline & Estimated $\boldsymbol{\beta}$ & SE (est. $\beta$ ) & Estimated OR & $\begin{array}{c}\text { 95\% CI } \\
\text { (for OR) }\end{array}$ & p-value \\
\hline Covariates & & & & & \\
\hline Age & -0.04 & 0.01 & 0.96 & $0.94-0.99$ & $0.008^{*}$ \\
$\begin{array}{l}\text { Single/Divorced vs } \\
\quad \text { Married/Living w/ Someone }\end{array}$ & 0.75 & 0.34 & 2.12 & $1.10-4.08$ & $0.03^{*}$ \\
$\begin{array}{l}\text { Changed Sexual Behavior vs } \\
\quad \text { Not }\end{array}$ & 1.48 & 0.33 & 4.38 & $2.31-8.30$ & $<0.0001^{*}$ \\
\hline \hline & & & & & \\
$*$ Max-rescaled R-sq = 0.25 & & & &
\end{tabular}

who had been tested for HIV. On the other hand, these were also persons who were more likely to have attempted suicide $(\mathrm{p}=0.07)$ and had changed their sexual behavior in last 12 months $(\mathrm{p}=0.05)$.

Similarly, significant predictors for persons who practiced safer sex (versus had not practiced safer sex) were age, marital status and recent change in sexual behavior. Persons who were younger $(\mathrm{p}=0.008)$ and were single or divorced $(p=0.03)$ were more likely to practice safer sex than their older or married counterparts. These were also likely to be persons who had changed their sexual behavior in the last 12 months $(\mathrm{p}<$ $0.0001)$.

\section{Discussion}

Rural California American Indians who have been HIV tested are younger, more highly educated and report a constellation of high-risk behaviors and traumatic past events that may have contributed to HIV risks and concerns. Our study sample reported several risky behaviors (consuming alcohol, having suicide ideation, and reporting suicide attempts) which were significantly greater among those who did not have HIV testing. It is known that persons who abuse alcohol are more likely to engage in highrisk sexual behaviors that increase their exposure to HIV infection as alcohol increases impulsivity and lowers inhibition (Kalichman, Simbayi, Vermaak, Jooste, \& Cain, 2008; Mokdad, Marks, Stroup \& Gerberding, 2004; Murray, Kulkarni, Michaud et al., 2006). In Baldwin and colleagues' (2000) study exploring alcohol as a risk factor for HIV transmission among American Indians many participants reported having unprotected sex with complete strangers, or unprotected sex with persons they 
would not have accepted as life partners, after excessive drinking. Indeed our study found that alcohol use, young age, higher education and a recent change in sexual behavior were predictors of HIV testing among our sample of rural California Indians.

Although suicide ideation is a risk factor that is more commonly reported than suicide attempts in the general population, both suicide ideation and attempts are more likely reported among HIV positive individuals who also have other psychological problems (Gliatto \& Rai, 1999). Our study on those who have had a HIV test reported that they had significantly increased suicide ideation and attempts. This finding, along with alcohol consumption forms a group of characteristics that is of concern, especially given that this cohort also reported that they were sexually abused during childhood and as adults. Self-reported history of sexual abuse in childhood and adulthood raises important questions regarding the trajectory of events (e.g., sexual abuse in childhood) experienced by participants, the effect on high risk behaviors, and the impact of these events over time. Reported history of sexual abuse in childhood and corresponding high risk behaviors has been documented by several studies (Brennan et al., 2007; Paul et al., 2001). These studies report that those individuals at risk for HIV/AIDS have unsafe sexual practices and have experienced childhood sexual abuse. The trauma of such abuse leaves lasting damage and is thought to influence high-risk behaviors as the individual matures.

Our study findings provide insight into behaviors and potential motivation for those who do or do not practice safer sexual behaviors. The people reporting safer sexual practices were significantly younger, not married, had lower household income, were somewhat more educated and were not in a monogamous relationship. Although they did not report significant neglect, sexual abuse and physical abuse, a large proportion reported some risky behavior being a cigarette smoker, although intending to quit smoking in the near future.

Our study sample did not report significantly higher experiences with neglect, sexual abuse or physical abuse in childhood, adolescence or adulthood. Rather, those who reported that they did not practice safer sexual behaviors may have reasoned that they had no reason for such measures as they were older, married and/or in a monogamous relationship. Although there was no difference in alcohol consumption, those who did not practice safer sex were more likely to smoke cigarettes and to report that they intend to quit smoking in the very near future (within 30 days).

Studies indicate that most adults who learn that they are HIV-positive continue to be sexually active (Bingman et al., 2001; Wenger et al., 1994). Persons engaging in unprotected sexual behaviors carry the threat of HIV/AIDS and secondary infections, risking themselves and their sex partners (Wenger, 1994). Marks (2006), recommends that the HIV/AIDS epidemic can be lessened substantially by increasing the number of HIV-positive persons who are aware of their status. There may be many reasons why individuals did not seek testing for HIV, or do not practice safer sex, including the possibility of denial, fear, threat of stigma, poor access to healthcare, trust issues, misinformation and violence.

Those individuals in our study who are living in rural areas may often not test for HIV due to limited access to testing facilities and because of concerns about confidentiality in close-knit communities where encounters at clinics with family, friends or acquaintances are likely (CDC, 2008). It is thought that many American Indians receive their diagnosis of HIV infection so late in the course of infection that they cannot participate in beneficial early treatment and management of modalities. Late diagnosis may be due to poorly funded programs that are not capable of providing standard, regular services needed for HIV prevention and screening. Further, the isolated locations of many of the 
Indian healthcare clinics may contribute to poor referral and limited service provision or access.

Increased HIV education, raising awareness about risks and testing procedures facilitating access to appropriate screening and enabling safer sexual behaviors may counteract the stigma and other concerns of screening. Improving reporting systems that ensure patient confidentiality and facilitating easier access to condoms, educational materials, and other materials that help to inform and assist safer sexual behaviors is necessary. Improved provider communication regarding safer sexual practices is also needed.

In a multi-clinic study of care providers and HIV clients, Marks (1999) reports that 29\% of the study sample had not been counseled by a clinic provider regarding safer sex. Additionally, clinic providers communicated to patients less about HIV disclosure to sex partners than about practicing safer sex. While HIV and AIDS were not reported as medically diagnosed conditions, Marks' study finds that participants are concerned, and that the American Indian population is at risk for HIV infection. Evidence of concern about HIV risk was found in the sample's reporting of having had their blood tested for HIV. Based on significant evidence from our study and other studies, there is a great need for targeted safer sex education, particularly about practicing safer sex and increasing HIV testing among the California American Indian population. There is also a great need for further exploration into the history held by American Indians in areas of sexual abuse, high risk behaviors and suicide ideation and attempts. The trajectory of events that leads to high-risk behaviors such as many of the behaviors that lead to high incidence of HIV, needs to be better understood by both researchers and American Indian community members so that culturally-appropriate interventions can be designed, implemented and sustained. Our research provides a profile of rural California Indians who report whether or not they have had HIV testing and practice safer sexual behaviors. Study findings are significant and fill a gap in the body of knowledge regarding American Indians and safer sexual practices and HIV testing.

\section{Limitations of the Study}

There are several limitations of the study that need to be identified. The self-selection of the clinics who agreed to participate in the study, the cross-sectional study design, self-reporting, and missing data on safer sexual behaviors and drug usage are limitations of the study. The small sample of male participants may be due to increased single family households headed by women or simply that males were not at home or chose not to identify as a household member when our survey staff administered the questionnaire. There is potential for bias in population-based surveys arising from possible absence of study subjects from the household when the surveys are being administered. Also, the household may not adequately represent the high-risk non-household population groups and mobile or transient populations. Because California has a very large population of American Indians (over 330,000) and because time and financial constrains limited access to all residents, the author chose to randomly sample a small portion of households of adult clinic users residing at participating sites.

\section{Acknowledgement}

This research was supported by a grant from the National Institute for Nursing Research, NIH, R01 NR04528. Briana Cardoza, MPH, Tracy Line Itty, MPH, and Fernando Martinez are to be recognized and thanked for their assistance in editing and formatting of the manuscript for publication.

\section{References}

Baldwin, J.A., Maxwell, C.J., Fenaughty, A.N., Trotter, R.T., \& Stevens, S.J. (2000). Alcohol as a risk factor for HIV transmission among American Indian and Alaska Native drug users. American Indian and Alaska Native Mental Health Research, 9, 1-17. 
Bingman, C.R., Marks, G., \& Crepaz, N. (2001). Attributions about one's HIV infection and unsafe sex in seropositive men who have sex with men. AIDS Behaviour, 5:283-289.

Bolu, O.O., Lindsey, C., Kamb, M.L., Kent, C., Zenilman, J., Douglas, J.M., Malotte, C.K., Rogers, J., \& Peterman, T.A., Project RESPECT Study Group. (2004). Is HIV/sexually transmitted disease prevention counseling effective among vulnerable populations?: a subset analysis of data collected for a randomized, controlled trial evaluating counseling efficacy (Project RESPECT). Sexually Transmitted Diseases, 31, 469-474.

Brennan, D.J., Hellerstedt, W.L., Ross, M.W. \& Welles, S.L. (2007). History of Childhood Sexual Abuse and HIV Risk Behaviors in Homosexual and Bisexual Men, American Journal of Public Health. 97(6):1107-1112.

Bureau of Indian Affairs. (2008). BIA quick facts. Retrieved September 15, 2009 from: http://www.doi.gov/bia/quick_facts.html.

Centers for Disease Control and Prevention (CDC). (2008). CDC HIV/AIDS fact sheet: HIV/AIDS among American Indians and Alaska Natives. Retrieved September 15, 2009 from http://www.cdc.gov/hiv/resources/factsheets/PDF/aian.pdf.

Centers for Disease Control and Prevention (CDC). (2004). Voluntary HIV testing as part of routine medical care: Massachusetts, 2000. Morbidity and Mortality Weekly Report, 53, 543-546.

Centers for Disease Control and Prevention (CDC). (1998) Behavioral Risk Factor Surveillance System Survey Questionnaire. Atlanta, Georgia: U.S. Department of Health and Human Services, Centers for Disease Control and Prevention.

Darbes, L., Crepaz, N., Lyles, C., Kennedy, G., \& Rutherford, G. (2008). The efficacy of behavioral interventions in reducing HIV risk behaviors and incident sexually transmitted diseases in heterosexual African Americans. AIDS, 22, 1177-1194.

Foley, K., Duran, B., Morris, P., Lucero, J., Jiang, Y., Baxter, B., Harrison, M., Shurley, M., Shorty, E., Joe, D., Iralu, J., Davidson-Stroh, L., Foster, L., Begay, M.G., \& Sonleiter, N. (2005). Using motivational interviewing to promote HIV testing at an American Indian substance abuse treatment facility. Journal of Psychoactive Drugs, 37, 321-329.

Gliatto, M.K., \& Rai, A.K. (1999). Evaluation and Treatment of Patients with Suicidal Ideation, American Family Physician, March 15, 1999, pp.1500-13.

Hosmer, D.W., \& Lemeshow, S. (2000). Applied Logistic Regression, 2nd edition, New York: John Wiley and Sons, Inc.

Indian Health Service. (2009). California Area Office, Retrieved August 27, 2009 from: http://www.ihs.gov/FacilitiesServices/areaOffices/California/uploadedfiles/GPRA/FY2007UserP opbyServiceUnitCountyandTribe.pdf.

Kalichman, S.C., Simbayi, L., Jooste, S., Vermaak, R., \& Cain, D. (2008). Sensation seeking and alcohol use predict HIV transmission risks: Prospective study of sexually transmitted infection clinic patients, Cape Town, South Africa. Addictive Behavior. Retrieved June 19, 2010 from http://www.sciencedirect.com/science?_ob=ArticleURL\&_udi=B6VC9-

4T4J88K3\&_user=4423\&_rdoc $=1 \&$ fmt $=$ \&_orig $=$ search \&_sort=d \&view=c\&_version=1\&_urlV ersion=0\&_userid $=4423 \&$ md5 $=1292$ b1eb821bf500bacdabd5f294dedc.

Lapidus, J.A., Bertolli, J., McGowan, K., \& Sullivan, P. (2006). HIV-related risk behaviors, perceptions of risk, HIV testing, and exposure to prevention messages and methods among urban American Indians and Alaska Natives. AIDS Education and Prevention, 18, 546-559.

Marks, G., Crepaz, N., \& Janssen, R.S. (2006). Estimating sexual transmission of HIV from persons aware and unaware that they are infected with the virus in the USA. AIDS, 20(10),1447-1450.

Marks, G., Burris S., \& Peterman, T.A. (1999). Reducing sexual transmission of HIV from those who know they are infected; the need for personal and collective responsibility. AIDS, 13, 297-306.

Marsiglia, F.F., Nieri, T., \& Stiffman, A.R. (2006). HIV/AIDS protective factors among urban American Indian youths. Journal of Health Care for the Poor and Underserved, 17, 745-758.

Mokdad, A.H., Marks, J.S., Stroup, D.F., \& Gerberding, J.L. (2004). Actual causes of death in the United States, 2000. JAMA, 291, 1238-1245. 
Murray, C.J., Kulkarni, S.C., Michaud, C., Tomijima, N., Bulzacchelli, M.T., Iandiorio, T.J., \& Ezzati, M. (2006). Eight Americas: investigating mortality disparities across races, counties, and racecounties in the United States. PloS (Public Library of Science) Med, 3, e260.

Paul, J,P., Catania. J., Pollack. L., Stall, R. (2001). Understanding childhood sexual abuse as a predictor of sexual risk-taking among men who have sex with men: The Urban Men's Health Study. Child Abuse and Neglect, 25, 557-584

Statistical Analysis System, SAS (Version 9.1) (statistical software) Cary, NC.

U.S. Commission on Civil Rights. (2003). A quiet crisis: Federal funding and unmet needs in Indian Country. US Commission on Civil Rights publication. Accessed June 19, 2010 from http://www.usccr.gov/pubs/na0703/na0204.pdf.

U.S. Department of Health and Human Services (USDHHS). (2000). Healthy People 2010. $2^{\text {nd }}$ ed. With Understanding and Improving Health and Objectives for Improving Health. 2 vols. Washington, DC: U.S. Government Printing Office. Retrieved June 21, 2010 from http://www.healthypeople.gov/Document/HTML/Volume1/13HIV.htm.

Wenger, S.N., Kusseling, F.S., Beck, K., \& Shapiro, M.F. (1994). Sexual behavior of individuals infected with the human immunodeficiency virus. The need for intervention. Archive of Internal Medicine $154,1849-1854$.

\author{
Author Information \\ Felicia S. Hodge, Dr.P.H., Professor* \\ University of California, Los Angeles \\ School of Nursing \\ School of Public Health \\ 700 Tiverton Ave. \\ Room 5-940 Factor Bldg. \\ Los Angeles, CA 90095-1702 \\ Telephone: (310) 267-2255 \\ Facsimile: (310) 206-3241 \\ Email: fhodge@sonnet.ucla.edu \\ Karabi Sinha, Ph.D. \\ University of California, Los Angeles \\ School of Nursing and Department of Biostatistics \\ School of Public Health \\ * corresponding author
}

